\title{
Unintentional Continuation of Medications Intended for Acute Illness After Hospital Discharge: A Population-Based Cohort Study
}

\author{
Damon C. Scales, MD, PhD $1,2,3,4$, Hadas D. Fischer, MD, MSc ${ }^{3}$, Ping Li, PhD ${ }^{3}$, \\ Arlene S. Bierman, MD, MS $3,4,6,8,17$, Olavo Fernandes, PharmD $4,9,10$, \\ Muhammad Mamdani, PharmD, MA, MPH $3,4,8,9$, Paula Rochon, $M D, M P H^{3,4,6,7}$, \\ David R. Urbach, MD, MSc $c^{3,4,12}$, and Chaim M. Bell, MD, PhD $3,4,5,6$
}

\begin{abstract}
'Department of Critical Care Medicine, Sunnybrook Health Sciences Centre, Toronto, ON, Canada; ${ }^{2}$ Interdepartmental Division of Critical Care and Department of Medicine, University of Toronto, Toronto, Canada; ${ }^{3}$ Institute for Clinical Evaluative Sciences, Toronto, Canada; ${ }^{4}$ Institute of Health Policy, Management and Evaluation, University of Toronto, Toronto, Canada; '5 Department of Medicine, Mount Sinai Hospital, New York, NY, USA; 'Department of Medicine, University of Toronto, Toronto, Canada; 'Women's College Research Institute, Women's College Hospital, Toronto, Canada; ${ }^{8} \mathrm{Li}$ Ka Shing Knowledge Institute of St. Michael's Hospital, Toronto, Canada; ' 2 Leslie Dan Faculty of Pharmacy, University of Toronto, Toronto, Canada; ${ }^{10}$ Department of Pharmacy, University Health Network (UHN), Toronto, Canada; " Lawrence S. Bloomberg Faculty of Nursing, University of Toronto, Toronto, Canada; ${ }^{12}$ Department of Surgery, University of Toronto, Toronto, Canada.
\end{abstract}

BACKGROUND: Patients are vulnerable to medicationrelated errors during transitions in care. Patients discharged from acute care hospitals may be at an elevated risk for the unintentional continuation of medications prescribed to prevent or treat complications that are associated with acute illness but are no longer indicated. We sought to evaluate rates of (primary objective) and risk factors for (secondary objective) potentially unintentional medication continuation following hospitalization.

METHODS: A population-based cohort study of more than one million patients 66 years of age or older who were hospitalized in Ontario, Canada, between 2003 and 2011 and followed for 1 year (2004 to 2012). We created distinct cohorts by identifying seniors not previously receiving four classes of medications typically used to treat or prevent complications of acute illness: (1) antipsychotic medications, (2) gastric acid suppressants (histamine-2 blockers and proton pump inhibitors), (3) benzodiazepines, and (4) inhaled bronchodilators and steroids. After excluding documented indications, we followed patients to ascertain whether these medications were continued after hospital discharge, and assessed risk factors for their continuation using generalized estimating equations. The primary outcome was the new dispensation of any of the selected medications within 7 days of hospital discharge.

RESULTS: Prescription without documented indication occurred across all medication classes, from 12,209 patients (1.4\%) for antipsychotic medications to 34,140 patients (6.1\%) for gastric acid suppressants. Risk factors for unintentional continuation varied across medication groups, but rates were consistently higher for older patients, those with multiple comorbidities, and emergency hospitalizations. The largest absolute risk factor across all

Electronic supplementary material The online version of this article (doi:10.1007/s11606-015-3501-5) contains supplementary material, which is available to authorized users.

Received June 3, 2015

Revised August 1, 2015

Accepted August 10, 2015

Published online September 14, 2015 medications was a hospitalization $>7$ days [OR $2.03(95 \%$ CI 1.94-2.11) for respiratory inhalers, 6.35 (95\% CI 5.916.82) for antipsychotic medications]. These medications were often continued at 1 year of follow-up, and accounted for a total additional medication cost of over CAD\$18 million for the study population.

CONCLUSION: Discharged patients are at risk of being prescribed and dispensed medications that are typically intended to prevent or treat complications of acute illness, despite having no documented indication for chronic use.

KEY WORDS: medication errors; prescriptions; continuity of patient care; cohort studies; hospitalizations; polypharmacy; aged.

J Gen Intern Med 31(2):196-202

DOI: $10.1007 / \mathrm{s} 11606-015-3501-5$

(C) Society of General Internal Medicine 2015

\section{INTRODUCTION}

Gaps in the continuity of patient care have been identified as a major area for improvement in patient safety for the reduction of preventable adverse outcomes ${ }^{1}$. An expanding body of evidence has demonstrated that improving continuity of care, including communication strategies between clinicians, is feasible, appreciated, and associated with improved patient outcomes. $^{2-9}$ Accordingly, understanding transfer errors between outpatient and inpatient settings can help in developing methods of intervention and, consequently, improved patient care. ${ }^{10-14}$

Complex hospitalized patients may be particularly vulnerable to communication failures between providers. Errors may occur as a consequence of multiple transitions between care areas (for example, between the intensive care unit (ICU) and medical wards) and a focus on the acute illness. ${ }^{15-17}$ These patients are also frequently receiving multiple medications and have multiple comorbidities, increasing their risk for adverse events related to polypharmacy and drug-drug interactions. ${ }^{18}$

We have previously demonstrated that hospitalization is associated with the unintentional discontinuation of 
medications used to treat chronic diseases ${ }^{17}$. We also wondered whether hospitalization might result in the unintentional continuation after discharge of selected medications that were intended only for temporary management of an acute illness or its complications. We used population-based databases to identify all seniors in Ontario not previously prescribed selected medications and followed them to determine whether these medications were continued after hospital discharge.

\section{METHODS}

We conducted a population-based cohort study using linked health data from April 1, 2002, to March 31, 2012, to analyze all Ontario residents aged 66 years and older who were discharged alive after hospitalization. We assessed whether they were newly dispensed any of four study medications commonly used to treat or prevent acute problems arising in-hospital.

\section{Setting and Databases}

We used seven linked population-based databases to conduct this research: (1) the Canadian Institute for Health Information Discharge Abstract Database (DAD), which contains data on all acute care hospitalizations and procedures; (2) the Same-Day Surgery database; (3) the Ontario Drug Benefits (ODB) database, which includes all outpatient medications dispensed to persons aged $>65$ years in the province of Ontario; (4) the Ontario Health Insurance Plan (OHIP) database, which contains data about fee-for-service physician billings; (5) the National Ambulatory Care Reporting System (NACRS), which contains information on emergency departments visits; (6) the Ontario Mental Health Reporting System, which includes mental health inpatient hospitalizations data; and (7) the Registered Persons Database (RPDB), which contains information on all deaths. Excellent agreement has been found comparing these databases and information obtained through chart audit. ${ }^{19-21}$ These databases are held securely in a linkable, de-identified form and analyzed at the Institute for Clinical Evaluative Sciences.

\section{Study Participants}

We identified all individuals aged $\geq 66$ years who were discharged alive from an acute care hospital from April 1, 2003, through January 31, 2011. This time frame enabled us to study healthcare events and medications dispensed for all patients that occurred in the 1 year prior to and 425 days following the acute hospitalization. We excluded palliative and chronic care hospitalizations, transfers between hospitals, episodes for which length of hospitalization was $\leq 1$ day, and patients who did not survive beyond 7 days after hospital discharge. We also excluded those with any hospitalizations during the 6 months prior to the index hospitalization in order to prevent confounding from the previous hospital admission. We allowed for multiple hospitalizations for the same patient as long as the inclusion and exclusion criteria continued to be met.

\section{Selected Medications}

Using this hospitalized cohort, we then created four distinct medication cohorts, each comprising patients who had no prior or acute indication for any of the following medication groups: (1) antipsychotic medications, (2) benzodiazepines, (3) gastric acid suppressants (histamine-2 blockers and proton pump inhibitors), and (4) inhaled bronchodilators and steroids (Fig. 1). All of these are commonly used in the elderly and represent medications where harm has been clearly described in this population. ${ }^{22-25}$ For each medication class we excluded patients who had received the medication during the year prior to hospitalization or whose admission was associated with a clear clinical indication for receiving that medication before (i.e. 1 year) or for continuing the medication after hospital discharge (e.g. the development of gastrointestinal bleeding during the hospital episode and subsequent dispensing of a proton pump inhibitor). We searched for these indications using diagnoses or fee codes found in prior hospitalization records and using physician inpatient and outpatient medical claims (eTable 1). This approach to identifying medication continuation after hospital discharge is similar to that used in prior research. ${ }^{26}$

\section{Outcomes}

Within each cohort, the primary outcome was medication continuation after discharge from the hospital. We defined this outcome as the new dispensation of the selected medication within 7 days of hospital discharge. The 7-day period was chosen to strengthen the association with exposure to hospitalization. ${ }^{27}$ This outcome could occur independent of a physician appointment. Secondary analyses examined prescriptions occurring within 30 days of hospital discharge. Patients dispensed medications within 7 days were followed for a maximum of 425 days to identify chronic use, defined as an additional claim for the same medication within 60 days of the 1-year anniversary (i.e. from 305 to 425 days post-index date).$^{28}$ We examined risk factors for medication continuation after hospital discharge by restriction to the following subgroups: patients with emergency admission, patients with an ICU admission during the hospitalization, and patients with hospital length of stay $>7$ days. We also estimated costs for dispensation without a documented indication for all selected medications over 1 year of follow-up. These estimates were based on total actual medication costs paid by the Ontario Drug Benefit Program.

Analysis. Each medication cohort was analyzed separately. Generalized estimating equations were used to examine the effect of patient (age, sex, income quintile, number of medications dispensed in prior year, Deyo-adapted Charlson comorbidity index) and hospitalization characteristics (emergency vs. other hospitalization, length of hospital stay, ICU admission during hospitalization, transfer from nursing home) on dispensing of medication after hospital discharge, after 


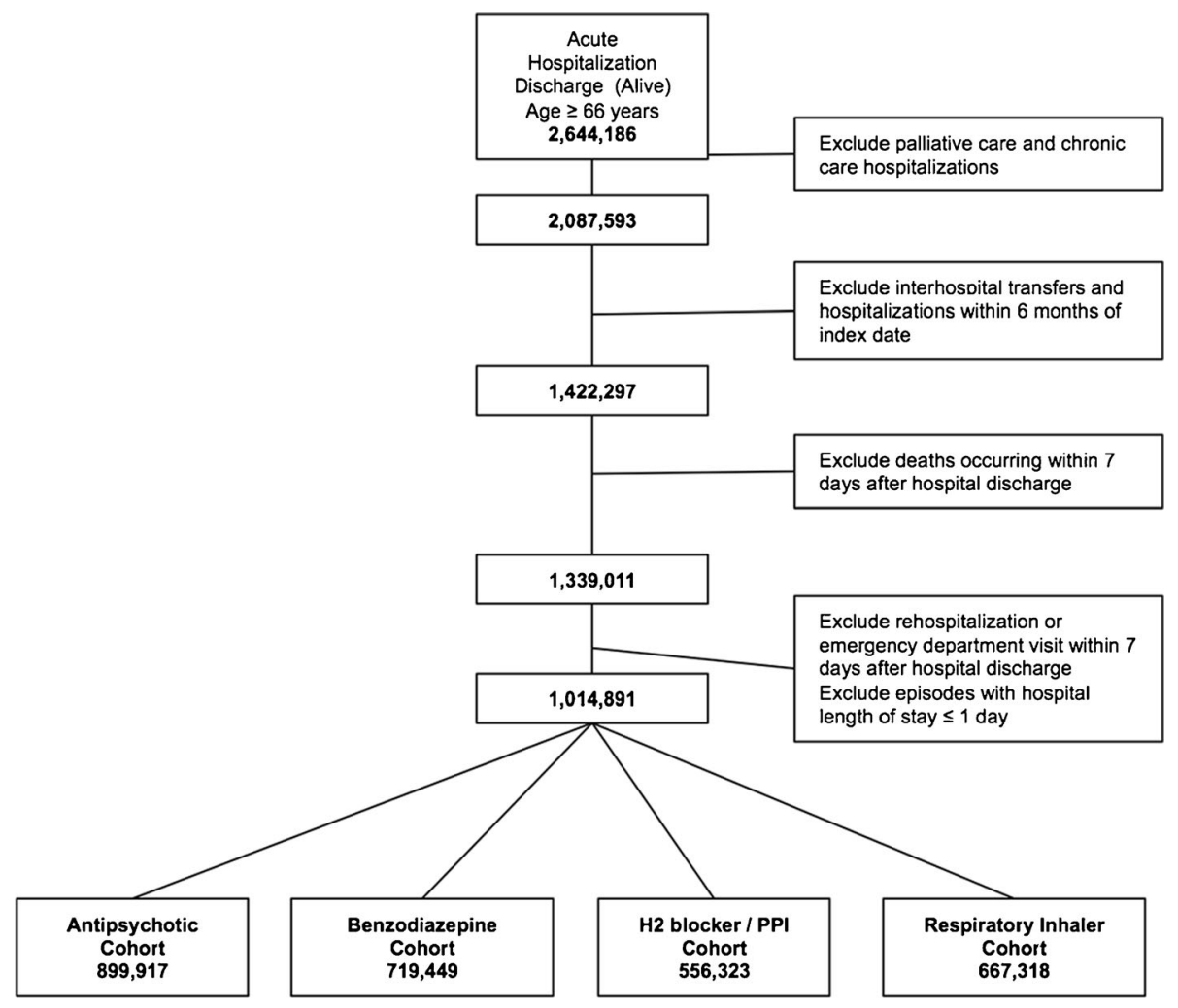

Fig. 1 Cohort creation. This figure describes the creation of the study cohorts. After excluding hospitalizations for palliative and chronic care, hospitalizations that included inter-hospital transfers, those with recent previous hospitalizations, and early death or re-hospitalization (within 7 days), the primary cohort consisted of $1,014,891$ patients $\geq 66$ years of age. This cohort was further subdivided according to use of the selected study medications after discharge. To create each medication class, we excluded patients who had received the medication during the year prior to hospitalization or whose admission was associated with a clear documented clinical indication for receiving that medication before (i.e. 1 year) or for continuing the medication after hospital discharge (see eTable).

adjusting for clustering of patients within hospitals. ${ }^{29-31} \mathrm{We}$ also conducted post hoc analyses to assess for temporal trends in rates of unintentional medication continuation by adding year of study into the final models. All analyses were performed using SAS software version 9.3 (SAS Institute Inc., Cary, NC, USA).

Ethics. All datasets were linked using unique encoded identifiers and were analyzed at the Institute for Clinical Evaluative Sciences (ICES). This study was approved by the institutional review board at Sunnybrook Health Sciences Centre, Toronto, Canada.

\section{RESULTS}

Characteristics of Discharged Patients. During the study period, 1,014,891 patients $\geq 66$ years of age were discharged alive from the hospital and eligible for inclusion (Fig. 1). Of these, about one-half were women and had a documented comorbidity. Study patients had received a median of nine different medications during the previous year (Table 1). Overall 1-year mortality following hospitalization was $13.5 \%$. A minority $(9.9 \%)$ were discharged to nursing homes. The medication cohorts ranged in size from 556,323 (no prior use or documented indication for gastric acid suppressant) to 899,917 patients (no prior use or documented indication for antipsychotic medications; Fig. 1).

Continuation of Temporary Medications. Continuation without documented indication occurred across all medication classes, from 12,209 patients (1.4\%) for antipsychotic medications to 34,140 patients $(6.1 \%)$ for gastric acid suppressants (Table 2). These rates of continuation after discharge were higher when measured at 30 days following hospital discharge, from 15,242 patients $(1.7 \%)$ for antipsychotic medications to $43,690(7.9 \%)$ patients for gastric acid suppressants.

These medications were often continued at 1 year of followup (Table 2). Rates of chronic use over 1 year were highest for gastric acid suppressants $(14,925 ; 2.7 \%)$. The total 1 -year cost of these medications was over CAD $\$ 18$ million for the study cohorts (range $\$ 632,475$ for benzodiazepine use to $\$ 10,876,911$ for gastric acid suppressants).

Risk Factors for Medication Continuation. Risk factors for continuation of these medications within 7 days of hospital discharge varied across medication groups, but rates were 
Table 1 Patient Characteristics

\begin{tabular}{|c|c|c|c|c|c|}
\hline & & TOTAL & $\begin{array}{l}\text { Emergency } \\
\text { admission }\end{array}$ & ICU & $\begin{array}{l}\text { Hospital } \\
\text { LOS }>7 \text { days }\end{array}$ \\
\hline & & $n=1,014,891$ & $n=767,712$ & $n=123,609$ & $n=312,512$ \\
\hline \multicolumn{6}{|l|}{ Baseline characteristics } \\
\hline Age (years) & Mean \pm SD & $77.8 \pm 7.4$ & $78.9 \pm 7.5$ & $76.2 \pm 6.8$ & $79.4 \pm 7.5$ \\
\hline Sex (female) & & $549,185(54.1 \%)$ & $429,136(55.9 \%)$ & $54,572(44.1 \%)$ & $179,031(57.3 \%)$ \\
\hline \multirow[t]{6}{*}{ Income quintile } & Lowest & $220,665(21.7 \%)$ & $176,416(23.0 \%)$ & $25,987(21.0 \%)$ & $72,871(23.3 \%)$ \\
\hline & Next to lowest & $214,889(21.2 \%)$ & $164,618(21.4 \%)$ & $26,350(21.3 \%)$ & $66,867(21.4 \%)$ \\
\hline & Middle & $197,575(19.5 \%)$ & $148,984(19.4 \%)$ & $24,224(19.6 \%)$ & $60,300(19.3 \%)$ \\
\hline & Next to highest & $190,381(18.8 \%)$ & $140,234(18.3 \%)$ & $23,701(19.2 \%)$ & $56,908(18.2 \%)$ \\
\hline & Highest & $187,203(18.4 \%)$ & $134,088(17.5 \%)$ & $22,826(18.5 \%)$ & $54,228(17.4 \%)$ \\
\hline & Unavailable & $4178(0.4 \%)$ & $3372(0.4 \%)$ & $521(0.4 \%)$ & $1338(0.4 \%)$ \\
\hline Number of medications in previous year & Median (IQR) & $9(6-14)$ & $10(6-14)$ & $9(6-13)$ & $10(6-14)$ \\
\hline \multirow[t]{3}{*}{ Charlson comorbidity index score } & 0 & $425,956(42.0 \%)$ & $287,631(37.5 \%)$ & $33,725(27.3 \%)$ & $89,369(28.6 \%)$ \\
\hline & 1 & $262,313(25.8 \%)$ & $228,324(29.7 \%)$ & $37,068(30.0 \%)$ & $87,445(28.0 \%)$ \\
\hline & $\geq 2$ & $326,622(32.2 \%)$ & $251,757(32.8 \%)$ & $52,816(42.7 \%)$ & $135,698(43.4 \%)$ \\
\hline Dementia & & $174,063(17.2 \%)$ & $160,541(20.9 \%)$ & $12,347(10.0 \%)$ & $73,494(23.5 \%)$ \\
\hline Primary care visits during previous year & Median (IQR) & $5(3-8)$ & $6(3-9)$ & $5(3-8)$ & $6(3-9)$ \\
\hline Specialist visits during previous year & Median (IQR) & $2(1-3)$ & $1(1-3)$ & $2(1-4)$ & $2(1-3)$ \\
\hline Nursing home residency & & $66,896(6.6 \%)$ & $64,291(8.4 \%)$ & $3900(3.2 \%)$ & $23,023(7.4 \%)$ \\
\hline \multicolumn{6}{|l|}{ Admission characteristics } \\
\hline Teaching hospital & & $271,254(26.7 \%)$ & $182,702(23.8 \%)$ & $41,596(33.7 \%)$ & $87,690(28.1 \%)$ \\
\hline Rural hospital & & $84,872(8.4 \%)$ & $77,499(10.1 \%)$ & $9814(7.9 \%)$ & $26,136(8.4 \%)$ \\
\hline Hospital length of stay & Mean \pm SD & $8.53 \pm 14.35$ & $9.44 \pm 15.87$ & $11.11 \pm 15.98$ & $18.58 \pm 22.74$ \\
\hline \multirow[t]{2}{*}{ ICU length of stay } & Mean \pm SD & $0.42 \pm 1.84$ & $0.44 \pm 1.90$ & $3.44 \pm 4.19$ & $0.88 \pm 3.05$ \\
\hline & Median (IQR) & $0(0-0)$ & $0(0-0)$ & $2(1-4)$ & $0(0-0)$ \\
\hline Mechanical ventilation & & $36,338(3.6 \%)$ & $19,175(2.5 \%)$ & $34,147(27.6 \%)$ & $24,214(7.7 \%)$ \\
\hline Mechanical ventilation duration & Mean \pm SD & $0.12 \pm 1.14$ & $0.10 \pm 1.14$ & $0.92 \pm 3.14$ & $0.31 \pm 2.01$ \\
\hline Mortality - 30 days & & $14,774(1.5 \%)$ & $14,152(1.8 \%)$ & $1,284(1.0 \%)$ & $7,694(2.5 \%)$ \\
\hline Mortality - 1 year & & $137,023(13.5 \%)$ & $125,228(16.3 \%)$ & $13,899(11.2 \%)$ & $62,996(20.2 \%)$ \\
\hline Discharge to nursing home & & $100,572(9.9 \%)$ & $96,455(12.6 \%)$ & $6,379(5.2 \%)$ & $55,076(17.6 \%)$ \\
\hline
\end{tabular}

consistently higher for emergent hospitalizations, older patients, and those with multiple comorbidities (Table 3). Some risk factors-for example, ICU admission during hospital stay-increased the risk of continuation for some medications but decreased the risk for others. The greatest absolute risk factor across all medication groups was longer hospitalization. The increased odds ratio for medication continuation after a hospitalization lasting more than 7 days ranged from 2.03 (95\% CI 1.94-2.11) for respiratory inhalers to 6.35 (95\% CI 5.91-6.82) for antipsychotic medications. In post hoc analyses, we observed no consistent temporal trends in rates of medication continuation during the study period (eTable). For example, rates of continuation of benzodiazepines after hospitalization decreased (odds ratio 0.95 per study year, $95 \%$ CI 0.94-0.96), whereas rates of continuation of gastric acid suppressants increased (odds ratio 1.04 per study year, 95 \% CI 1.03-1.06; eTable 2).

In additional sensitivity analysis, we examined how frequently patients in each medication cohort subsequently developed an acceptable indication for chronic use of the medication during 1 year of follow-up. For example, among the 12,209 patients receiving newly prescribed antipsychotic medications after hospital discharge, only 1050 (8.6 \%) subsequently developed an accepted indication during 1 year of follow-up. Similarly, the rates of developing acceptable indications for chronic medication use during follow-up remained low in each of the medication cohorts: $2.5 \%(589 / 23,806)$ for benzodiazepines, $9.0 \%(3080 / 34,140)$ for gastric acid suppressants, and $17.8 \%(2578 / 14,469)$ for respiratory inhalers. However, a larger proportion of the patients still using these

Table 2 Continuation of Temporary Medications after Hospital Discharge

\begin{tabular}{|c|c|c|c|c|}
\hline & $\begin{array}{l}\text { Antipsychotic } \\
\text { cohort }\end{array}$ & $\begin{array}{l}\text { Benzodiazepine } \\
\text { cohort }\end{array}$ & $\begin{array}{l}\text { Gastric acid suppressant } \\
\text { cohort }\end{array}$ & $\begin{array}{l}\text { Respiratory inhaler } \\
\text { cohort }\end{array}$ \\
\hline & $(n=899,917)$ & $(n=719,449)$ & $(n=556,323)$ & $(n=667,318)$ \\
\hline $\begin{array}{l}\text { Prescription within } 7 \text { days of discharge } \\
\text { Prescription within } 30 \text { days of discharge } \\
\text { Chronic use over } 1 \text { year* } \\
1 \text {-year cost of medication (\$CAD) }{ }^{\dagger}\end{array}$ & $\begin{array}{l}12,209(1.4 \%) \\
15,242(1.7 \%) \\
5101(0.6 \%) \\
3,942,634\end{array}$ & $\begin{array}{l}23,806(3.3 \%) \\
36,282(5.0 \%) \\
5352(0.7 \%) \\
632,475\end{array}$ & $\begin{array}{l}34,140(6.1 \%) \\
43,690(7.9 \%) \\
14,925(2.7 \%) \\
10,876,911 \\
\text { Total cost }(\$ C A D)^{\dagger}\end{array}$ & $\begin{array}{l}14,469(2.2 \%) \\
18,994(2.8 \%) \\
3880(0.6 \%) \\
3,241,023 \\
18,693,043\end{array}$ \\
\hline
\end{tabular}

${ }^{*}$ Patients dispensed medications within 7 days were followed for a maximum of 425 days to identify chronic use, defined as an additional claim for the same medication within 60 days of the 1-year anniversary date (i.e. from 305 to 425 days post-index date)

${ }^{t}$ Reflects total actual cost of the selected medications prescribed to individuals in the year following hospital discharge

Abbreviations: $C A D=$ Canadian dollar 
Table 3 Predictors of Medication Continuation after Hospital Discharge

\begin{tabular}{|c|c|c|c|c|c|}
\hline & & $\begin{array}{l}\text { Antipsychotic } \\
\text { cohort }\end{array}$ & $\begin{array}{l}\text { Benzodiazepine } \\
\text { cohort }\end{array}$ & $\begin{array}{l}\text { Gastric aid } \\
\text { suppressant } \\
\text { cohort }\end{array}$ & $\begin{array}{l}\text { Respiratory } \\
\text { inhaler cohort }\end{array}$ \\
\hline & & $\begin{array}{l}(n=899,917) \\
\text { OR }(95 \% \text { CI })\end{array}$ & $\begin{array}{l}(n=719,449) \\
\text { OR }(95 \% \text { CI })\end{array}$ & $\begin{array}{l}(n=556,323) \\
\text { OR }(95 \% \text { CI })\end{array}$ & $\begin{array}{l}(n=667,318) \\
\text { OR }(95 \% \text { CI })\end{array}$ \\
\hline Age & (per 10 years) & $1.76(1.70-1.82)$ & $1.03(1.01-1.06)$ & $1.02(1.00-1.05)$ & $1.27(1.23-1.30)$ \\
\hline Sex & (female vs. male) & $0.87(0.84-0.90)$ & $1.16(1.12-1.19)$ & $1.14(1.08-1.20)$ & $0.92(0.89-0.95)$ \\
\hline Income quintile & Highest vs. Lowest & $0.98(0.92-1.04)$ & $0.97(0.93-1.00)$ & $0.96(0.92-1.01)$ & $0.83(0.79-0.87)$ \\
\hline \multirow{3}{*}{ Medications in prior year } & $7-9$ vs. $0-6$ & $0.75(0.72-0.79)$ & $0.97(0.95-1.00)$ & $1.05(1.02-1.08)$ & $1.01(0.97-1.06)$ \\
\hline & $10-14$ vs. $0-6$ & $0.62(0.59-0.65)$ & $0.93(0.90-0.96)$ & $1.04(1.01-1.07)$ & $1.09(1.04-1.14)$ \\
\hline & $15+$ vs. $0-6$ & $0.53(0.50-0.56)$ & $0.92(0.89-0.96)$ & $1.06(1.02-1.10)$ & $1.16(1.10-1.22)$ \\
\hline \multirow[t]{2}{*}{ Charlson comorbidity index score } & 1 vs. 0 & $2.47(2.30-2.64)$ & $1.20(1.16-1.25)$ & $1.09(1.05-1.14)$ & $1.31(1.26-1.37)$ \\
\hline & $\geq 2$ vs. 0 & $2.16(2.03-2.29)$ & $1.23(1.17-1.29)$ & $1.30(1.21-1.40)$ & $1.53(1.47-1.60)$ \\
\hline Admission category & Emergent vs. other & $2.75(2.44-3.10)$ & $1.35(1.20-1.51)$ & $1.71(1.32-2.23)$ & $2.84(2.40-3.36)$ \\
\hline Length of hospital stay & $>7$ days versus $\leq 7$ days & $6.35(5.91-6.82)$ & $2.66(2.53-2.80)$ & $2.15(2.05-2.25)$ & $2.03(1.94-2.11)$ \\
\hline ICU during hospital & ICU admission vs. none & $0.68(0.62-0.74)$ & $1.20(1.08-1.33)$ & $2.37(1.99-2.81)$ & $1.51(1.40-1.63)$ \\
\hline Nursing home residency & (from nursing home vs. none) & $1.66(1.50-.83)$ & $1.82(1.65-2.01)$ & $0.91(0.85-0.96)$ & $2.11(2.00-2.23)$ \\
\hline
\end{tabular}

medications at 1 year had developed an acceptable indication during follow-up: $20 \%$ (1050/5101) for antipsychotics, $11 \%$ (589/5352) for benzodiazepines, $21 \%(3080 / 14,925)$ for gastric acid suppressants, and $66 \%(2578 / 3880)$ for respiratory inhalers].

\section{DISCUSSION}

We examined more than one million hospitalizations of seniors in Canada's largest province and found that medications typically intended for short-term use during acute illness were sometimes continued after discharge. We found that such continuation without documented indication occurred across all medication classes that we studied. We identified several risk factors, but highest at risk were older patients, those with multiple comorbidities, and those with emergent hospitalizations. Notably, hospital stay longer than 7 days put patients at much greater risk of post-discharge continuation of the studied medications. These findings are important, because receiving medications without indication places patients at unnecessary risk for medication-related adverse events. Although the relative rates of unintentional medication continuation were modest, the absolute number of affected individuals was large. In addition, the healthcare costs were substantial.

Our findings are consistent with smaller single-centre and single-drug studies. For example, an increased risk of initiating benzodiazepines has been observed following hospitalizations that included ICU admission. ${ }^{26}$ Previous reports have suggested that ICU admission might be a risk factor for initiation of antipsychotic prescriptions after discharge because these medications are often used transiently to treat delirium in critically ill patients. ${ }^{32}$ However, in our study we found lower rates of antipsychotic continuation in this subgroup. We can only speculate that hospitalists and other clinicians may be more attuned to the temporary indication for these medications and are thus more apt to discontinue them after transfer from ICU to the ward. The highest rates and associated costs related to continuing medications without documented indication following discharge in our study were observed with gastric acid suppressants. Even higher rates and costs of post-hospital continuation of these medications have been reported, although the prior study was restricted to critically ill patients. ${ }^{33}$

Our choice of medication groups for this study represents different theorized approaches to medication-prescribing, medication-taking, and medication-dispensing practice. ${ }^{34,35}$ They include medications for the treatment of symptomatic diseases and for preventing complications of acute illness. They represent different medication delivery systems (e.g. tablets, inhalers). A few are medications used to treat chronic conditions (e.g. gastric acid-suppressing drugs for gastroesophageal reflux) that may be confused with evidence-based prophylactic ICU therapies (e.g. gastric acid-suppressing drugs to prevent gastric stress ulcers). ${ }^{25}$ However, the selected medications are unlikely to be appropriately prescribed for long-term use following a single hospitalization in the absence of an acceptable indication. Prescription of any of these medications when not medically indicated would be associated with increased inconvenience, cost, and inappropriate disease labeling. In addition, unnecessary medications lead to preventable polypharmacy and drug interactions, and expose patients to potential harm, with no apparent benefit. Furthermore, the delivery of appropriate medical treatments (and avoidance of inappropriate therapies) based on established indications has become an important topic for health care professionals, policymakers, funding bodies, and the general public. ${ }^{36,37}$

Our population-based estimates that account for clustering of patients within hospitals help overcome issues related to generalizability and local prescribing patterns. We tested our hypothesis across multiple groups of medications, reinforcing the notion that unintentional medication continuation is not a problem isolated to a single drug class or disease. In addition, our large sample size allowed us to identify risk factors associated with new prescriptions of these medications. Our research should have practical implications in the identification of medication classes that require more careful reassessment during transitions in care. 
Our study does have limitations. We were able to measure rates of post-discharge prescriptions of the selected medications, but cannot prove with our data that these were not appropriately started for a new but undocumented indication that arose during hospitalization. Specifically, an appropriate indication may have been documented in the health record but not included as a discharge diagnosis code. This type of misclassification could have caused us to overestimate rates of unintentional continuation after hospital discharge. However, the selected medication groups are seldom indicated for long-term use in the absence of a documented appropriate indication. Furthermore, we used broad exclusion criteria to ensure that true indications for receiving these medications were not present during the year preceding hospitalization. Another limitation is that prescriptions in our database were presumed to relate to the acute hospitalization because of the close temporal relationship to hospital discharge. It is possible but unlikely that some individuals developed a new but undocumented indication for these medications during the 7 days following hospital discharge. Although we detected no consistent temporal trends in rates of unintentional continuation during the study period, we were also unable to identify hospitals that had already implemented medication reconciliation programs. The existence of such programs could reduce the inappropriate continuation of temporary medications beyond hospital discharge, and therefore we may have underestimated the magnitude of this problem in other jurisdictions. Finally, total costs as estimated in our study may change where drug costs and generic medication market shares differ; however, this is unlikely to alter the overall high cost of ongoing but non-indicated medication use across all groups observed in our study.

\section{CONCLUSION}

We found that hospitalized patients are at risk of being discharged with prescriptions for medications typically used to prevent or treat complications of acute illness, despite having no documented indication for chronic use. These prescriptions are associated with substantial costs and may place patients at risk for subsequent harm, with no apparent benefit.

Conflict of Interest: The authors declare that they do not have a conflict of interest.

Source of Funding: This research was funded by a Chair in Patient Safety and Continuity of Care from the Canadian Patient Safety Institute and Canadian Institute for Health Research. The funding body had no role in the design or conduct of the study.

This study was supported by the Institute for Clinical Evaluative Sciences (ICES), which is funded by an annual grant from the Ontario Ministry of Health and Long-Term Care (MOHLTC). The opinions, results, and conclusions reported in this paper are those of the authors and are independent from the funding sources. No endorsement by ICES or the Ontario MOHLTC is intended or should be inferred.

Parts of this material are based on data and information compiled and provided by CIHI. However, the analyses, conclusions, opinions, and statements expressed herein are those of the authors, and not necessarily those of CIHI.
Author Information: DCS is supported by the Graham Farquharson Fellowship in Translational Health Research from the Physicians' Services Incorporated Foundation. CMB holds a Chair in Patient Safety and Continuity of Care from the Canadian Patient Safety Institute and Canadian Institute for Health Research.

Transparency Declaration: The lead authors (Damon Scales and Chaim Bell) affirm that the manuscript is an honest, accurate, and transparent account of the study being reported, that no important aspects of the study have been omitted, and that any discrepancies from the study as planned have been explained.

Authors' Contributions: Conception and oversight of study: DCS and $C M B$

Design of study: DCS, CMB, HDF, PL, ASB, OF, MM, PR, DRU

Analytical plan/analyses: DCS, CMB, HDF, PL

Drafting of manuscript: DCS, CMB

Editing of manuscript for intellectual content: DCS, CMB, HDF, PL, ASB, $O F, M M, P R, D R U$

Corresponding Author: Damon C. Scales, MD, PhD; Department of Critical Care Medicine, Sunnybrook Health Sciences Centre, 2075 Bayview Avenue, Room D108, Toronto, ON, Canada M4N 3M5 (e-mail:damon.scales@sunnybrook.ca).

\section{REFERENCES}

1. Cook RI, Render M, Woods DD. Gaps in the continuity of care and progress on patient safety. BMJ. 2000;320(7237):791-794.

2. van der Kam WJ, de Meyboom JB, Tromp TF, Moorman PW, van der Lei J. Effects of electronic communication between the GP and the pharmacist. The quality of medication data on admission and after discharge. Fam Pract. 2001;18(6):605-609.

3. van Walraven C, Seth R, Austin PC. A. L. Effect of discharge summary availability during post-discharge visits on hospital readmission. J Gen Intern Med. 2002;17(3):186-192.

4. van Walraven C, Mamdani M, Fang J. PC. A. Continuity of care and patient outcomes after hospital discharge. J Gen Intern Med. 2004; 19(6):624-631.

5. Branger PJ, van der Wouden JC, Schudel BR. Electronic communication between providers of primary and secondary care. BMJ. 1992;305(6861):1068-1070.

6. van Walraven C. E. R. What is necessary for high-quality discharge summaries? Am J Med Qual. 1999;14(4):160-169.

7. van Walraven C, Laupacis A, Seth R, Wells GF. Dictated versus databasegenerated discharge summaries: a randomized clinical trial. CMAJ Can Med Assoc J. 1999;160(3):319-326.

8. van Walraven C. AL. W. Quality assessment of a discharge summary system. CMAJ Can Med Assoc J. 1995; 152(9):1437-1442.

9. Kripalani S, LeFevre F, Phillips CO, Williams MV, Basaviah P, Baker DW. Deficits in communication and information transfer between hospitalbased and primary care physicians: implications for patient safety and continuity of care 1. JAMA. 2007;297(8):831-841.

10. Kripalani S, Jackson AT, Schnipper JL, Coleman EA. Promoting effective transitions of care at hospital discharge: a review of key issues for hospitalists. [Review] [108 refs]. J Hospital Med (Online). 2007;2(5):314-323.

11. Institute for Health I. Getting Started Kit: Prevent Adverse Drug Events (Medication Reconciliation). 2005; http://www.ihi.org/resources/Pages/ Tools/HowtoGuidePreventAdverseDrugEvents.aspx. Accessed July 31, 2015.

12. Schnipper JL, Hamann C, Ndumele CD, et al. Effect of an electronic medication reconciliation application and process redesign on potential adverse drug events: a cluster-randomized trial. Arch Intern Med. 2009; 169(8):771-780.

13. Boockvar KS, Carlson LH, Giambanco V, Fridman B, Siu A. Medication reconciliation for reducing drug-discrepancy adverse events. Am J Geriatric Pharmacother. 2006;4(3):236-243.

14. Pronovost $\mathbf{P}$, Weast $\mathbf{B}$, Schwarz $\mathbf{M}$, et al. Medication reconciliation: a practical tool to reduce the risk of medication errors. J Crit Care. 2003; 18(4):201-205.

15. Cullen DJ, Sweitzer BJ, Bates DW, Burdick E, Edmondson A, Leape LL. Preventable adverse drug events in hospitalized patients: a comparative study of intensive care and general care units. Crit Care Med. 1997;25(8): 1289-1297. 
16. Rothschild JM, Landrigan CP, Cronin Jw, et al. The Critical Care Safety Study: The incidence and nature of adverse events and serious medical errors in intensive care. Crit Care Med. 2005;33(8):1694-1700.

17. Bell CM, Brener SS, Gunraj N, et al. Association of ICU or hospital admission with unintentional discontinuation of medications for chronic diseases 1. JAMA. 2011;306(8):840-847.

18. Bronskill SE, Gill SS, Paterson JM, Bell CM, Anderson GM, Rochon PA. Exploring variation in rates of polypharmacy across long term care homes. J Am Med Dir Assoc. 2012;13(3):309 e315-321.

19. Naylor CD, Anderson GM, Goel v. Patterns of health care in Ontario. Toronto: Institute for Clinical Evaluative Sciences; 1994.

20. Williams JI, Young W. A summary of studies on the quality of health care administrative databases in Canada. In: Goel V, Williams JI, Anderson GM, Blackerstein-Hersch P, Fooks C, Naylor CD, eds. Vol 2nd. Ottawa: Canadian Medical Association; 1996:339-345.

21. Juurlink D, Preyra C, Croxford R, et al. Canadian Institute for Health Information Discharge Abstract Database: A Validation Study. Toronto: Institute for Clinical Evaluative Sciences; 2006.

22. Sevransky JE, Levy MM, Marini JJ. Mechanical ventilation in sepsisinduced acute lung injury/acute respiratory distress syndrome: an evidence-based review. Crit Care Med. 2004;32(11 Suppl):S548-553.

23. Jacobi J, Fraser GL, Coursin DB, et al. Clinical practice guidelines for the sustained use of sedatives and analgesics in the critically ill adult. Crit Care Med. 2002;30(1):119-141.

24. Heyland DK, Dhaliwal R, Drover JW, Gramlich L, Dodek P. Canadian clinical practice guidelines for nutrition support in mechanically ventilated, critically ill adult patients. JPEN. J Parenter Enter Nutr. 2003;27(5):355-373.

25. Cook D, Guyatt G, Marshall J, et al. A comparison of sucralfate and ranitidine for the prevention of upper gastrointestinal bleeding in patients requiring mechanical ventilation. Canadian Critical Care Trials Group. N.Engl.J.Med. 1998;338(12):791-797.

26. Bell CM, Fischer HD, Gill SS, et al. Initiation of benzodiazepines in the elderly after hospitalization. J Gen Intern Med. 2007;22(7):1024-1029.
27. Jackevicius CA, Mamdani M, Tu JV. Adherence with statin therapy in elderly patients with and without acute coronary syndromes. JAMA. 2002;288(4):462-467.

28. Alam A, Gomes T, Zheng $\mathbf{H}$, Mandani M. Long-term analgesic use after low-risk surgery. Arch Intern Med. 2012;172:425-430.

29. Deyo RA, Cherkin DC, Ciol MA. Adapting a clinical comorbidity index for use with ICD-9-CM administrative databases. J Clin Epidemiol. 1992;45(6):613-9.

30. Schneeweiss S, Maclure M, Soumerai SB, Walker AM, Glynn RJ. Quasiexperimental longitudinal designs to evaluate drug benefit policy changes with low policy compliance. J Clin Epidemiol. 2002;55(8):833-841.

31. Schneeweiss S, Seeger JD, Maclure M, Wang PS, Avorn J, Glynn RJ. Performance of comorbidity scores to control for confounding in epidemiologic studies using claims data. Am J Epidemiol. 2001;154(9):854-864.

32. Jasiak KD, Middleton EA, Camamo JM, Erstad BL, Snyder LS, Huckleberry YC. Evaluation of discontinuation of atypical antipsychotics prescribed for ICU delirium. J Pharm Pract. 2013;26(3):253256.

33. Wohlt PD, Hansen LA, Fish JT. Inappropriate continuation of stress ulcer prophylactic therapy after discharge. Ann Pharmacother. 2007;41(10): 1611-1616.

34. Ong SW, Fernandes OA, Cesta A, Bajcar JM. Drug-related problems on hospital admission: relationship to medication information transfer. Ann Pharmacother. 2006;40(3):408-413.

35. Bajcar JM, Kennie N, Einarson TR. Collaborative medication management in a team-based primary care practice: an explanatory conceptual framework. Res Social Adm Pharm. 2005; 1(3):408-429.

36. Cassel CK, Guest JA. Choosing wisely: helping physicians and patients make smart decisions about their care. JAMA : J Am Med Assoc. 2012;307(17):1801-1802.

37. Brody H. Medicine's ethical responsibility for health care reform-the Top Five list. N Engl J Med. 2010;362(4):283-285. 